\title{
Matinhas, Paraíba - Brasil e suas variabilidades climáticas para a citricultura local
}

\author{
Matinhas, Paraíba - Brazil and its climate variabilities for local citriculture \\ Matinhas, Paraíba - Brasil y sus variabilidades climáticas para la citricultura local
}

\section{Resumo}

O objetivo é mostrar as contribuições dos elementos meteorológicos do município de Matinhas, visando um desenvolvimento sustentável nas áreas produtivas de citricultura, fruticultura e agricultura familiar. Os elementos meteorológicos estudados foram: temperatura máxima, média, mínima e amplitude térmica do ar, umidade relativa do ar, vento (intensidade e direção), insolação total, cobertura de nuvens, evaporação, evapotranspiração de referência, precipitação. Os dados de precipitações corresponderam à série de 2000-2018, fornecido pela Agência Executiva de Gestão das Águas do Estado da Paraíba. A temperatura média flutua entre $22{ }^{\circ} \mathrm{C}$ a $25,2{ }^{\circ} \mathrm{C}$, a temperatura máxima oscila de $27,3{ }^{\circ} \mathrm{C}$ a $31,5^{\circ} \mathrm{C}$ e a temperatura mínima fluem de $18,2{ }^{\circ} \mathrm{C}$ a $21,1{ }^{\circ} \mathrm{C}$. A variação da amplitude térmica é de $11,9{ }^{\circ} \mathrm{C}$ a $14,4{ }^{\circ} \mathrm{C}$. A umidade relativa do ar média oscila entre $72,8 \%$ no mês de novembro a $88 \%$ no mês de julho, a precipitação anual é de $956,7 \mathrm{~mm}$, observou-se que a marcha anual de umidade relativa do ar acompanha a distribuição anual da precipitação, porque a precipitação é o processo de alimentação das fontes naturais de vapor da água e umidade. A insolação total oscilou entre 134,8 a 240,2 horas e sua média anual é de $2.361,7$ horas. A evaporação anual é de $1.292,4 \mathrm{~mm}$ e a evapotranspiração anual é de $1.616,8 \mathrm{~mm}$, a intensidade do vento anual é 2,40 $\mathrm{ms}^{-1}$, com uma cobertura anual de nuvem de 0,81 décimos. O computo do Balanço hídrico para as CAD, $100 \mathrm{~mm}$ visando redução no consumo de energia e água, redução de tempo de uso de bomba d'água utilizado na irrigação. Palavras-chave: Variabilidade meteorológica; Produção agrícola; Balanço hídrico.

\begin{abstract}
The objective is to show the contributions of the meteorological elements of the municipality of Matinhas, aiming at sustainable development in the productive areas of citrus, fruit and family farming. The meteorological elements studied were: maximum, average, minimum temperature and air thermal amplitude, relative air humidity, wind (intensity and direction), total insolation, cloud cover, evaporation, reference evapotranspiration, precipitation. The rainfall data corresponded to the 2000-2018 series, provided by the Executive Agency for Water Management of the State of Paraíba. The average temperature fluctuates between $22{ }^{\circ} \mathrm{C}$ to $25.2{ }^{\circ} \mathrm{C}$, the maximum temperature fluctuates from $27.3{ }^{\circ} \mathrm{C}$ to $31.5{ }^{\circ} \mathrm{C}$ and the minimum temperature fluctuates from $18.2{ }^{\circ} \mathrm{C}$ to $21.1{ }^{\circ} \mathrm{C}$. The variation of the thermal amplitude is from $11.9^{\circ} \mathrm{C}$ to $14.4{ }^{\circ} \mathrm{C}$. The mean relative humidity ranges from $72.8 \%$ in November to $88 \%$ in July, annual precipitation is $956,7 \mathrm{~mm}$, it was observed that the annual rate of relative humidity follows the annual distribution of precipitation, because precipitation is the process of feeding natural sources of water vapor and moisture. Total insolation ranged from 134.8 to 240.2 hours and its annual average is $2,361.7$ hours. The annual
\end{abstract}


evaporation is $1292.4 \mathrm{~mm}$ and the annual evapotranspiration is $1616.8 \mathrm{~mm}$, the annual wind intensity is $2.40 \mathrm{~ms}-1$, with an annual cloud coverage of 0.81 tenths. The computation of the water balance for the CAD, $100 \mathrm{~mm}$ aiming at reducing energy and water consumption, reducing the time of use of the water pump used in irrigation.

Keyword: Weather variability; Agricultural production; Water balance.

\section{Resumen}

El objetivo es mostrar las contribuciones de los elementos meteorológicos del municipio de Matinhas, apuntando al desarrollo sostenible en las áreas productivas de citricultura, fruticultura y agricultura familiar. Los elementos meteorológicos estudiados fueron: temperatura máxima, media, mínima y amplitud térmica del aire, humedad relativa, viento (intensidad y dirección), insolación total, nubosidad, evaporación, evapotranspiración de referencia, precipitación. Los datos de precipitación correspondieron a la serie 2000-2018, proporcionada por la Agencia Ejecutiva de Gestión del Agua del Estado de Paraíba. La temperatura media fluctúa entre $22{ }^{\circ} \mathrm{C}$ y $25,2{ }^{\circ} \mathrm{C}$, la máxima va de $27,3{ }^{\circ} \mathrm{C}$ a $31,5^{\circ} \mathrm{C}$ y la mínima fluye de $18,2{ }^{\circ} \mathrm{C}$ a $21,1 \mathrm{oC}$. La variación del rango de temperatura es de $11,9^{\circ} \mathrm{C}$ a $14,4{ }^{\circ} \mathrm{C}$. La humedad relativa media oscila entre el $72,8 \%$ en el mes de noviembre y el $88 \%$ en el mes de julio, la precipitación anual es de $956,7 \mathrm{~mm}$, se observó que la marcha anual de la humedad relativa sigue la distribución anual de la precipitación, porque la precipitación es el proceso de alimentación de las fuentes naturales de vapor de agua y humedad. La insolación total osciló entre 134,8 y 240,2 horas y su media anual es de 2.361,7 horas. La evaporación anual es de 1.292,4 mm y la evapotranspiración anual de $1.616,8 \mathrm{~mm}$, la intensidad anual del viento es de 2,40 ms-1, con una nubosidad anual de 0,81 décimas. El cálculo del balance hídrico para la DAC, de $100 \mathrm{~mm}$, tiene como objetivo la reducción del consumo de energía y agua, la reducción del tiempo de uso de la bomba de agua utilizada en el riego.

Palabras clave: Variabilidad meteorológica; Producción agrícola; Balance hídrico.

\section{Introdução}

Segundo Machado et al. (2017) a climatologia regional é abrangida a partir das flutuações Climáticas e das variabilidades atmosféricas de determinada amostra de certo elemento climático (Menezes et al., 2015; RAMOS et al., 2017). Os estudos da climatologia se caracterizam com a finalidade inicial de diferenciação de áreas ou comparação entre áreas. Seja o estudo do clima ou de um elemento constituinte, uma climatologia se caracteriza em determinada porção do espaço e possibilita ao estudioso entender as flutuações espaço-climática na distribuição de seus elementos que atuam ou se formam em dada região ou área.

Os modelos Agrometeorológicos e a interpretação de dados climáticos relacionados com o crescimento, desenvolvimento e produtividade das culturas vem a fornecem subsídios os quais permitem ao setor agrícola tomar extraordinárias decisões para o controle de pragas e doenças estratégias, melhoramento d aprimoramento do planejamento do uso e ocupação do solo, adaptação de culturas, monitoramento, gerenciamento e previsão de safras, no dimensionamento de obras de engenharia hidráulica de micro e macrodrenagem para a estimativa da vazão, controle de irrigação e lazer estimativa de uma vazão (Lazinski, 1993). Entre as diversas atividades econômicas do município de Matinhas predomina o cultivo de produtos citricos (tendo como destaques a laranja cravo e a tangerina).

A pluviométrica é um dos elementos meteorológicas mais representativas e irregulares no planeta, pois a sua caracterização no seu regime para uma localidade, vem a auxilia no projeto e gerenciamento dos recursos hídricos, assim como, nas influências e condições ambientais (Menezes et al., 2016; Moura et al., 2015).

O estudo pluvial depende de diversos elementos como: clima, relevo, temperatura, umidade, velocidade do vento, insolação, fotoperíodo, evaporação e evapotranspiração, entre outros fatores) o que torna impossível a sua análise de modo determinístico, no entanto a sua estimativa pode ser realizada de modo mais simples com processos estocásticos (Righetto, 1998).

Medeiros et al. (2020) analisaram as oscilações das tendências térmicas, anuais das temperaturas extremas (mínima e máxima) para o município de Bom Jesus do Piauí, entre 1960-2018. Calcularam-se as médias mensais, anuais e estacionais para às estações: verão, outono, inverno e primavera. Os resultados indicaram o comportamento climático da área estudada de um período quente e/ou frio que devem servir de alerta às autoridades e tomadores de decisões para um melhor planejamento 
da agropecuário e do agronegócio. As flutuações das temperaturas decorrem dos sistemas sinóticos atuantes na época do período chuvoso e do período seco, assim como dos impactos ao meio ambiente e das atuações dos sistemas sinóticos transientes de larga escala e das escalas local e regional.

A evaporação, assim como a evapotranspiração, soma perdas d'água acentuadas para as áreas semiáridas do Brasil, sendo de grande importância à identificação dos fatores que afetam o balanço hídrico da região (Tucci, 2005). Um dos elementos climáticos de importância no estudo da economia de água dos reservatórios é a evapotranspiração visando uma utilização de forma racional. Isto porque o conhecimento do consumo d'água pelas culturas, ou seja, a evapotranspiração das culturas leva em consideração a precipitação e as perdas operacionais dos sistemas de irrigação (Sediyama, 1996).

Dantas et al. (2016), confrontou a exatidão dos métodos de Hargreaves-Samani e Camargo, em relação ao método de Penman-Monteith para as mesorregiões do estado da Paraíba, sua avaliação para os resultados indicou que o modelo de Hargreaves-Samani não necessitou de ajustes para região do agreste, mas o mesmo modelo não se ajustou à região da Borborema. Este resultado vem a corroborar com os discutidos neste artigo.

No período de inverno a diferença foi menor visto que nessa estação registra-se influência da radiação, temperatura e da velocidade do vento, que são variáveis importantes nos poderes evapotranspirativos e evaporativo d'água. Resultado semelhante foi encontrado nos estudos dos autores Hallal et al. (2013), Muniz et al. (2014) e Cardoso et al. (2014). Em estudo da variabilidade intra e interanual da bacia hidrográfica estudada, Piazza et al. (2017) também encontrou valores de ETP maiores no verão (janeiro a março) e menores durante o inverno (junho a agosto).

Assis et al. (2015), asseguraram que as mudanças do clima vêm apassivando cada vez mais a problemática da insuficiência hídrica, sobretudo em áreas áridas e semiáridas do planeta e em especial o semiárido do Nordeste do Brasil, por apresenta tendência à aridização, acompanhada de da alteração nos padrões pluviométricos, ocasionando redução da frequência e intensidade nos índices pluviais, ainda conforme os autores a região SNEB é caracterizada com elevada potencialidade para evaporação d'água, em função da grande disponibilidade de energia solar, temperaturas elevadas e da baixa umidade do ar.

Pereira et al, (2012), relataram que a mesorregião do Sertão Paraibano, apresenta uma maior taxa de água evapotranspirada, quando comparada as outras regiões. Os mesmos descreveram que, as mesorregiões do Sertão, Borborema e Agreste, possuem um baixo índice de precipitação, quando comparada à alta evapotranspiração anual ocorrida, sendo o maior volume pluviométrico advindo da região Litoral do Estado.

Costa et al, (2015), computaram as oscilações da evaporação no tanque classe "A" no município de Teresina- PI e realizaram comparação com as mudanças na urbanização ocorrida no período estudo, encontrando alterações nos índices evaporativos em face da ocupação do Homem e suas respectivas modificações no espaço. O bloqueio do vento devido ao crescimento horizontal está contribuindo para a redução da evaporação (EVR), o contrário ocorre quando chove, não havendo escoamento superficial e ao término da precipitação os índices evaporativos ocorrem em maiores proporções devido à troca de calor. Verificaram-se ainda que as oscilações de menores e maiores valores ocorridos, com destaque para as décadas 19761985 e 1986-1995 que apresentaram as menores variações. A década de 2006-2011 no mês de outubro apresentou a maior flutuação dos períodos estudados. Os índices evaporativos tiveram maiores significâncias a partir da década de 1996, devido à verticalização urbana, alteração da área vegetal, compactação do solo com a pavimentação, aterramento de lagoas e eutrofização dos espelhos da água.

Medeiros (2018), realizou o monitoramento da insolação como sendo esta atividade relevante para: agricultura, energia renovável e fonte de calor, analisou sua variabilidade decadal e comparou com a média histórica para as décadas 19621971; 1972-1981; 1982-1991; 1992-2001 e 2002-2011 para Recife - PE. Conclui que as incidencias da insolação acima dos padrões normais na área estudada está condicionada a baixa cobertura de nuvem, oscilação da temperatura acima da normalidade e a ocorrencia de queimadas, referenciou ainda que parte desta variabilidade interanual da insolação esta 
associada a ocorrencias dos consequências locais e regionais e as contribuições dos fenômenos de larga e meso escala atuantes na área estudada.

Kozmhinsky et al, (2018), marcaram as condições climáticas da insolação no Estado Pernambucano através da interpolação, elaborando mapas representativos da distribuição mensal e anual, além da variabilidade baixa e alta da insolação pelo método da krigagem.

Medeiros et al. (2018), relataram que no Estado do Piauí as altas incidência da insolação que chega a superfície é devido ao seu posicionamento junto do equador. A baixa cobertura de nuvens, as flutuações térmicas acima da normalidade e o registro de incêndios e queimadas vêm a condicionar as incidências de insolação nas regiões piauienses nos meses de julho a outubro. As oscilações estão unificadas às condições de atuações do Anticiclone Subtropical do Atlântico Sul, que inibi a formação de nuvens, favorece ao aumento do fluxo radiativo de ondas curtas do fluxo do saldo de radiação.

Tem-se como objetivo é mostrar as contribuições dos elementos meteorológicos do município de Matinhas, visando um desenvolvimento sustentável nas áreas produtivas de citricultura, fruticultura e agricultura familiar.

\section{Material e Métodos}

O município de Matinhas está inserido na unidade geoambiental do Planalto da Borborema, formada por maciços e outeiros altos, com altitude variando entre 650 a 1.000 metros. Ocupa uma área de arco que se estende do sul de Alagoas até o Rio Grande do Norte. O relevo é geralmente movimentado, com vales profundos e estreitos dissecados. Com respeito à fertilidade dos solos é bastante variada, com certa predominância de média para alta.

A área da unidade é recortada por rios perenes, porém de pequena vazão e o potencial de água subterrânea é baixo. A vegetação desta unidade é formada por Florestas Subcaducifólica e Caducifólica, próprias das áreas agrestes.

Figura 1. Posicionamento do município de Matinhas.

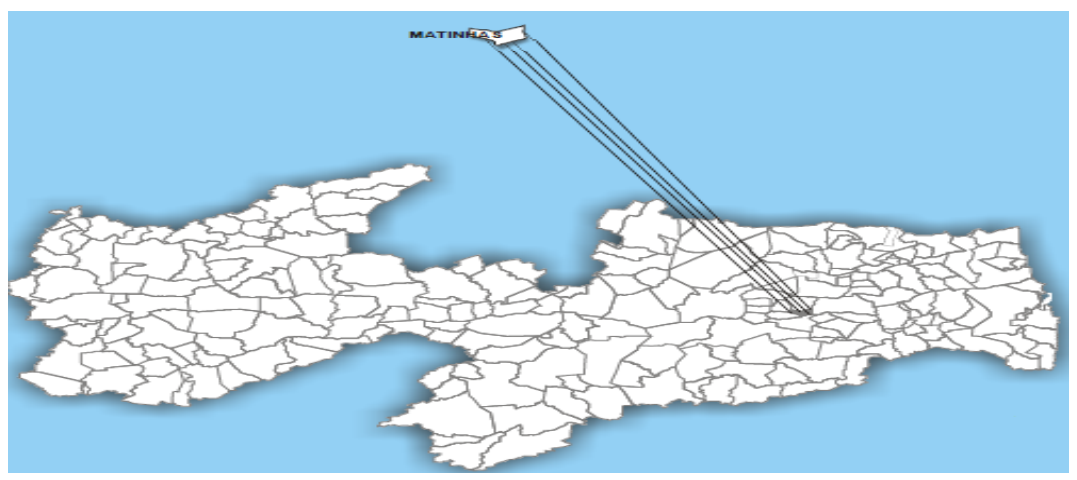

Fonte: CPRM (2006).

Para o desenvolvimento deste artigo utilizou-se de séries de dados mensais e anuais de precipitação referente ao período de 14 anos de dados observados (2000 - 2018), fornecido pela Agência Executiva de Gestão das Águas do Estado da Paraíba (AESA, 2019). Os dados de temperatura foram estimados pelo software Estima_T, (Cavalcanti et. al., 1994, Cavalcanti et. al., 2006).

Os dados de umidade relativa do ar; intensidade e direção predominante do vento, insolação total, cobertura de nuvens, foram estimadas a partir das estações meteorológicas convencionais do Instituto Nacional de Meteorologia (INMET, 2018) dos municípios circunvizinhos, compreendendo ao período de 1962 a 2010.

O Balanço Hídrico Climatológico foi realizado segundo a metodologia de (Thornthwaite et al., 1955), com estimativa da evapotranspiração potencial e evaporação real pelo método de (Thornthwaite 1948), por intermédio do programa 
computacional Balanço Hídrico Normal, usando-se uma planilha eletrônica Excel elaborada e disponibilizada por Medeiros (2013).

O clima é do tipo tropical chuvoso, com verão seco. A estação chuvosa se inicia em janeiro/fevereiro com término em setembro, podendo se estender até outubro.

Sobre regimes térmicos mais elevados, as plantas cítricas emitem vários surtos vegetativos e florais ao longo do ano, o que torna possível a existência de diversas épocas de colheitas. As várias colheitas obtidas ao longo do ciclo anual resultam em maior produtividade global das árvores quando comparadas com aquelas que vegetam em locais de temperaturas mais amenas.

A citricultura do Município de Matinhas ocupa uma área de 1.122 hectares (IBGE, 2004), distribuídos entre 421 produtores, apresentando-se como tipicamente de minifúndio familiar, dos quais $83 \%$ possuem até três membros da família envolvidos com a cultura e $68 \%$ dos citricultores estão na atividade há mais de 10 anos (LOPES et al., 2007). Com uma produção de 7,2 mil tonelada de tangerina em 2003, Matinhas ajudou a colocar a Paraíba na posição de maior produtor nordestino (12.631 toneladas) e sétima posição no ranking nacional (IBGE, 2004).

\section{Resultados e Discussões}

A pluviometria representa o atributo fundamental na análise dos climas tropicais, refletindo a atuação das principais correntes da circulação atmosférica. No município de Matinhas especificamente, as chuvas são fundamentais para o bom desenvolvimento do regime dos rios perenes, córregos, riachos, níveis dos lagos e lagoas, bem como para a ocupação do solo, sendo imprescindível ao planejamento de qualquer atividade o conhecimento da sua dinâmica.

O regime de precipitação que compreende o município de Matinhas, localizado na parte norte do Estado da Paraíba, insere-se na faixa das isoeitas (linha que une o mesmo valor de precipitação) de 900 e 1000 mm/ano.

No município de Matinhas, em geral, as chuvas iniciam-se por volta da segunda quinzena de janeiro, eleva seu volume nos primeiros dias de fevereiro e se prolonga até setembro sendo o quadrimestre mais chuvoso de abril a julho.

Os fatores provocadores de chuva no município são formações de linhas de instabilidade (LI) na costa e transportada para o interior pelos ventos alísios de sudeste/nordeste, desenvolvimento de aglomerados convectivos, proveniente do calor armazenado na superfície e transferido para atmosfera, orografia, contribuições de formação de vórtices ciclônicos de ar superior (VCAS), e tendo como principal sistema o posicionamento da Zona de Convergência Intertropical (ZCIT).

Normalmente as chuvas têm intensidade moderada (de tempo regular e por volta de oito a dez horas de chuvas descontínuas diárias), seguidas de irregularidade devido ás falhas dos sistemas meteorológicos atuantes. Salienta-se que a ocorrência de períodos de veranicos (ocorrências de vários dias consecutivos sem chuva durante o período chuvoso) no quadrimestre mais chuvoso (abril a julho) é possível e variante de ano para ano. Sua magnitude é variada dependendo da época e dos fatores meteorológicos. Tem-se registrado ocorrências com períodos de veranicos superiores a dezessete (17) dias mensais no intervalo de tempo ocorrido dentro do quadrimestre.

A Figura 2 mostra o gráfico da climatologia da precipitação, para o município de Matinhas, registrados para o período de 2000-2018.

A curva de precipitação climatológica nos mostra que durante o ano os índices pluviométricos são bastantes irregulares. Os meses que ocorrem as maiores quantidades de chuvas são de abril a julho com flutuações oscilando entre 102,7 a 173,2 mm/mês; nos meses de outubro a dezembro as precipitações são insignificantes para a agricultura, armazenagem e represamento de água no solo e açudes com valores totais mensais variando entre 13,2 a $18,7 \mathrm{~mm} / \mathrm{mês}$, a precipitação média anual é de 956,7 mm/ano. 
A variabilidade com que os totais anuais de chuva se sucedem, retratam o ritmo climático que está intimamente relacionado ao mecanismo da circulação atmosférica regional, devido às irregularidades espaciais e temporais na distribuição das chuvas.

A compreensão do ritmo climático se completa com a análise do regime pluvial, ou seja, da distribuição mensal das chuvas. Embora a área estudada tenha uma distribuição irregular de chuvas durante o ano, dois períodos se destacam, definindo um limite zonal bem marcante entre seco e chuvoso e vice-versa.

Figura 2. Gráfico da climatologia da precipitação para o município de Matinhas.

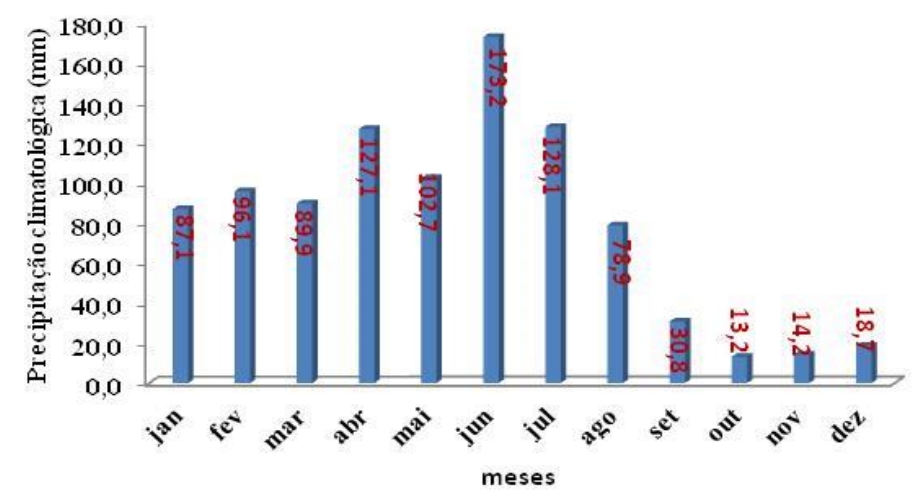

Fonte: Medeiros (2022).

Na Figura 3 observa-se a variabilidade espaço temporal dos índices de precipitações climatológicos, máximos e mínimos absolutos registrados para o período de 2000-2018. Os maiores índices pluviométricos máximos foram registrados entre os meses de janeiro a setembro, com flutuações de 135,6 em setembro do ano de 2000 a 429,3 mm no mês de janeiro do ano de 2004. Nos meses de setembro a outubro ocorrem os valores mínimos de precipitação, sou seja neste intervalo das mínimas não foram registradas chuvas. O maior e menor volume pluviométrico anual foi registrado nos anos de 2004 com $1.535,4 \mathrm{~mm}$ e no ano de $2006 \mathrm{com}$ um total anual de 560,8 $\mathrm{mm}$. Esta variabilidade é decorrente dos sistemas meteorológicos atuantes como os El Niño e La Niña.

Figura 3. Climatologia da precipitação máximos e mínimos absolutos para Matinhas.

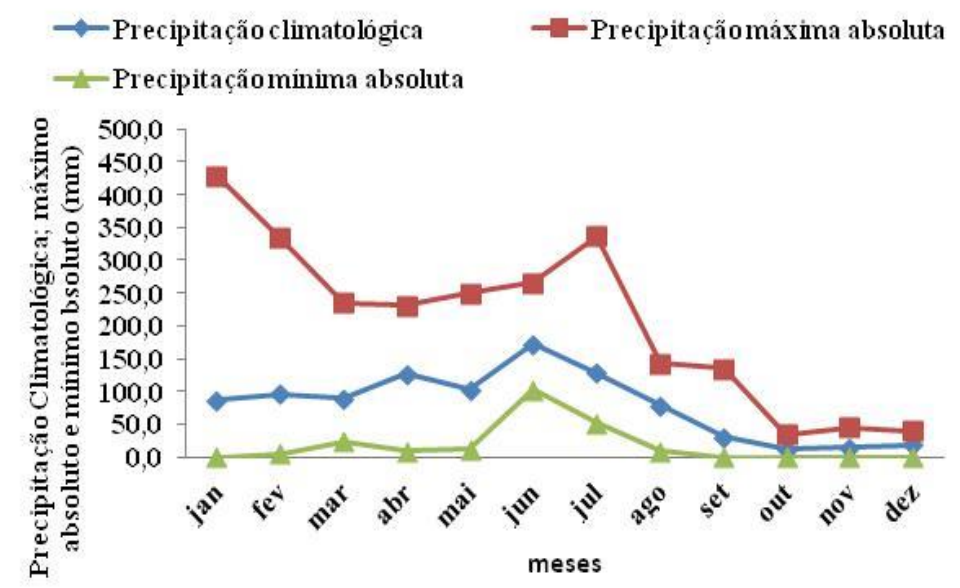

Fonte: Medeiros (2022). 
Em meio as atividades produtivas, a agricultura é a mais condicionada as variabilidades climáticas pluviais, de tal forma que estas são responsáveis por até $70 \%$ da variação final da produção (Ortolani et al., 1987).

\section{Temperaturas máxima, mínima, média, amplitude térmica e umidade relativa do ar}

Apesar de sua extensão territorial, o estado da Paraíba conta com um número reduzido de estações meteorológicas que medem e/ou registram dados de temperaturas. Para suprir essa limitação, bem como a questão do tempo necessário para obter valores médios representativos, tem sido usada a estimativa desse elemento climático, em função das coordenadas geográficas: latitude, longitude e altitude. Verificou-se que a latitude e longitude têm influência pouco significativa, se comparada com a altitude.

Figura 4. Demonstram os gráficos da climatologia das temperaturas máxima, mínima média e amplitude térmica $\left({ }^{\circ} \mathrm{C}\right)$, para Matinhas - Paraíba.

A variabilidade da temperatura máxima começa com aumento significativo a partir da segunda quinzena do mês de setembro e prolonga-se até o início da primeira quinzena do mês de maio com oscilações mensais fluindo entre $27,3{ }^{\circ} \mathrm{C}$ a 31,5 ${ }^{\circ} \mathrm{C}$. A temperatura máxima anual e de $29,8^{\circ} \mathrm{C}$.

A temperatura mínima anual é de $20^{\circ} \mathrm{C}$, sua flutuabilidade máximas ocorrem entre os meses de setembro a junho com oscilações de $19,1^{\circ} \mathrm{C}$ a $20,9^{\circ} \mathrm{C}$, os meses de julho e agosto são os meses de menores ocorrências de temperatura mínima com oscilações de $18,3^{\circ} \mathrm{C}$ e $18,2^{\circ} \mathrm{C}$, respectivamente.

Matinhas tem uma temperatura média anual de $23,9^{\circ} \mathrm{C}$ e suas oscilações mensais ocorrem entre $25,2^{\circ} \mathrm{C}$ (fevereiro) a $22^{\circ} \mathrm{C}$ no mês de junho. A amplitude térmica anual é $13,3{ }^{\circ} \mathrm{C}$ e suas oscilações mensais fluem entre $14,4{ }^{\circ} \mathrm{C}$ (novembro) a 11,9 ${ }^{\circ} \mathrm{C}$ (junho).

Figura 4. Gráfico da climatologia das temperaturas máxima, mínima, média e amplitude térmica, para Matinhas.

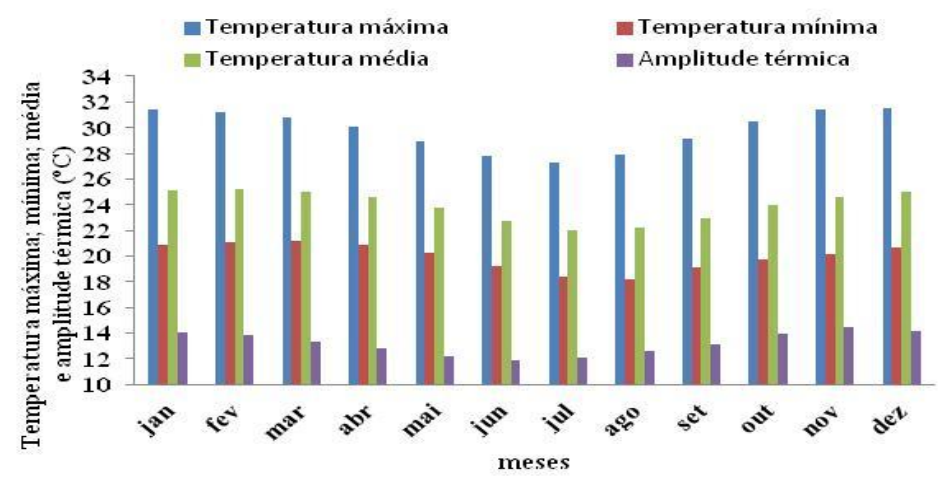

Fonte: Medeiros (2022).

Estas flutuações estão em conformidades com os estudos de (Marengo et al., 2008; Marengo et al., 2015; IPCC 2007; IPCC 2014; Medeiros 2016; Medeiros 2017; Rossato 2011; Nobre et al. 2005) mostraram que os índices térmicos têm semelhanças com os descritos neste artigo.

Em suma, (Figura 5) observar-se que a umidade relativa do ar para o município de Matinhas, apresenta média mensal variando de $72,8 \%$ no mês de novembro (mais baixa) a $88 \%$ no mês de julho (mais alta), com uma taxa anual de $79,2 \%$.

O trimestre de baixa umidade relativa do ar são os meses de outubro, novembro e dezembro e os meses de maio, junho e julho como os meses mais úmidos. 
Figura 5. Gráfico da climatologia da umidade relativa do ar, para o município de Matinhas.

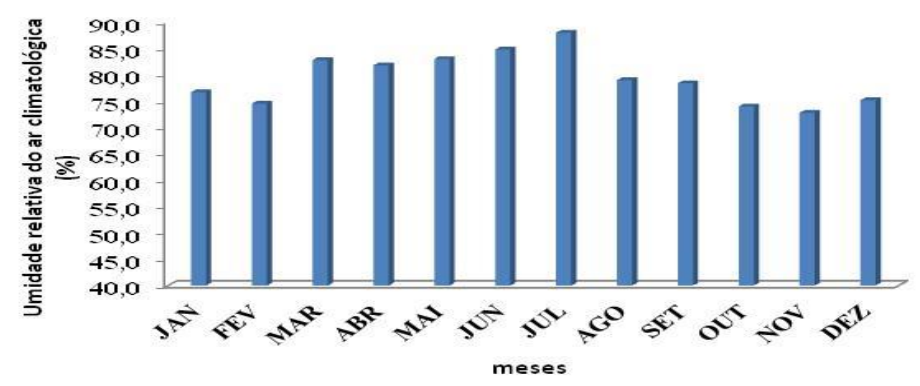

Fonte: Medeiros (2021).

\section{Ventos (intensidade e direção predominantes)}

O clima regional do Nordeste do Brasil (NEB) é regido pela zona de convergência intertropical (ZCIT). A ZCIT é uma região de convergência de ventos alísios de nordeste e sudeste do Atlântico e é caracterizada por uma presença intensa de nuvens tendo como ação quase permanente de centros de baixa pressão atmosférica. O posicionamento latitudinal sazonal da ZCIT determina tanto a presença dos ventos dominantes e do regime de chuvas (Philander \& Pacanowski, 1986).

A Figura 6 mostra o gráfico da intensidade climatológica do vento em $\mathrm{ms}^{-1}$ para Matinhas.

A intensidade climatológica do vento possui valores mensais entre 2,20 a 2,60 m/s. A intensidade média anual do vento nesta área é de $2,40 \mathrm{~m} / \mathrm{s}$.

Salientamos que nestes cálculos não foram computadas as rajadas de ventos, fato que ocorre quase que constantemente quando se encontra estacionário e permanente o centro de alta pressão nesta região.

A direção do vento é o ponto cardeal de onde vem o vento. A partir da rosa dos ventos obtêm-se a direção do vento predominante para determinado local e período.

A direção predominante do vento é a direção que ocorre em maior frequência. É decorrente da posição do local em relação aos centros de pressão atmosférica, sofrendo influência de obstáculos naturais junto ao solo. O relevo tem efeito muito pronunciado, podendo definir a direção predominante.

Figura 6. Gráfico da velocidade climatológica do vento, para o município de Matinhas.

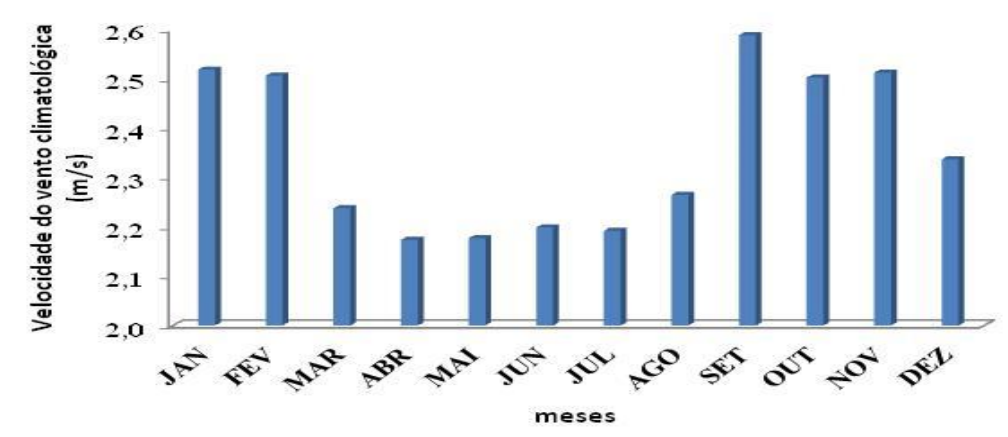

Fonte: Medeiros (2022).

O demonstrativo da direção do vento predominante no município é da seguinte forma conforme quadro abaixo: 
Tabela 1. Demonstrativo da direção mensal e anual climatológica do vento predominante para a área do município de Matinhas.

\begin{tabular}{|c|c|c|c|c|c|c|c|c|c|c|c|c|c|}
\hline PARÂMETROS/MESES & JAN & FEV & MAR & $\mathrm{ABR}$ & MAI & JUN & JUL & $\mathrm{AGO}$ & SET & OUT & NOV & DEZ & ANUAL \\
\hline DIREÇÃO VENTO & E-SE & E-SE & E-SE & E-SE & E-SE & SE & SE & E-SE & E-SE & E-SE & E-SE & E-SE & E-SE \\
\hline
\end{tabular}

Fonte: Medeiros (2022).

A direção predominante do vento anual no município é de E-SE. A direção predominante de E-SE ocorrem nos meses de janeiro, fevereiro, março, abril, maio, agosto, setembro, outubro, novembro e dezembro. A direção de SE é predominante dos meses de junho e julho. Pode-se concluir que os fatores provocadores de chuvas são característicos da predominância de ventos com maior frequência de entrada nas direções acima estabelecidas.

Com a alteração na direção do vento na superfície, sendo associada à ocorrência de precipitação, essa característica reveste-se de grande importância para o clima municipal.

\section{Evapotranspiração e Evaporação}

A evapotranspiração anual no município de Matinhas é de $1.616,8 \mathrm{~mm}$, observamos que a flutuação deste parâmetro mês a mês varia de 90,1 mm (junho menor valor) a 172,6 mm (janeiro máximo valor). Os meses com os menores valores de ETP são abril; junho e julho. Os meses de máximos valores são de outubro a janeiro, com flutuações entre 158,7 a 172,6 mm.

A evaporação e evapotranspiração foram obtidas através do Balanço Hídrico Climatológico realizado segundo a metodologia de (Thornthwaite 1948, Thornthwaite et al., 1955), para tal, utilizou-se o software desenvolvido em planilhas eletrônicas do Excel por (Medeiros, 2013).

Na Figura 7 observa-se o gráfico da climatologia da evapotranspiração, evaporação (mm), a Figura 9 gráficos climatológico da insolação total (hora e décimos) para o município de Matinhas.

A taxa anual de evaporação (EVR) é de 1.292,4 mm, bastante expressiva quando comparada com o índice anual de precipitação. Observa-se que a flutuação deste parâmetro mês a mês varia de: 75,7 mm (junho) a 136,5 mm (janeiro).

Os meses com as menores taxas de evaporação estendem-se entre junho e julho, com 75,7 mm e 79,7mm respectivamente. Já entre os meses setembro, outubro, janeiro e fevereiro os índices evaporativos são os maiores. Tais flutuações estão em conformidade com o Estudo de Matos et al. (2014).

Figura 7. Gráfico da climatologia de evaporação, evapotranspiração para o município de Matinhas.

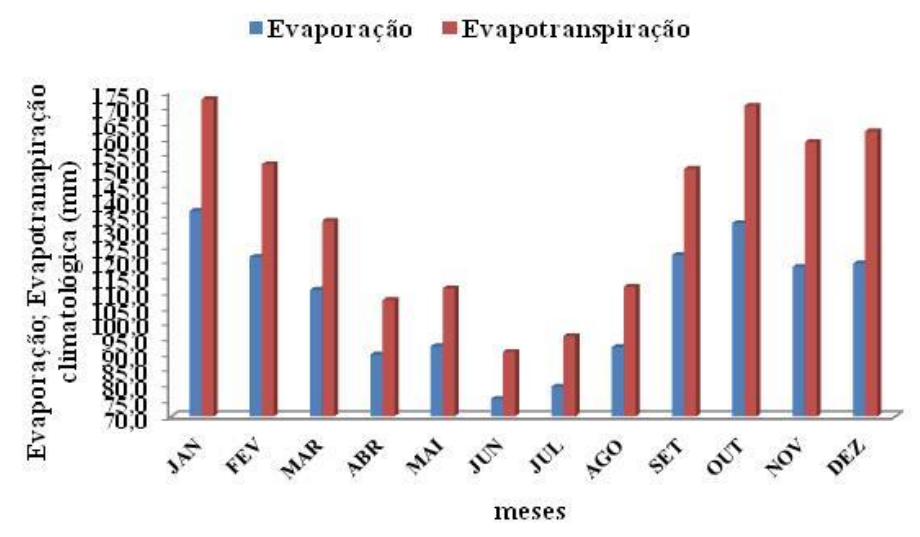

Fonte: Medeiros (2021). 


\section{Insolação e Nebulosidade}

No município de Matinhas, observa-se que a incidência da insolação começa a decrescer na segunda quinzena de março e mantém-se em queda até a primeira quinzena do mês de setembro, logo em seguida notamos um aumento excessivo da incidência da insolação até a primeira quinzena do mês de março.

Na Figura 8 observa-se o gráfico da climatologia da insolação total para o município de Matinhas. A insolação anual é de 2.361,7 horas. Os meses com maiores intensidades de insolação total estendem-se de agosto a março e nos meses de abril a julho, época do período chuvoso, a intensidade da insolação sofre redução. A insolação atua inversa e proporcionalmente à cobertura de nebulosidade.

Figura 8. Gráfico da climatologia da insolação total para o município de Matinhas.

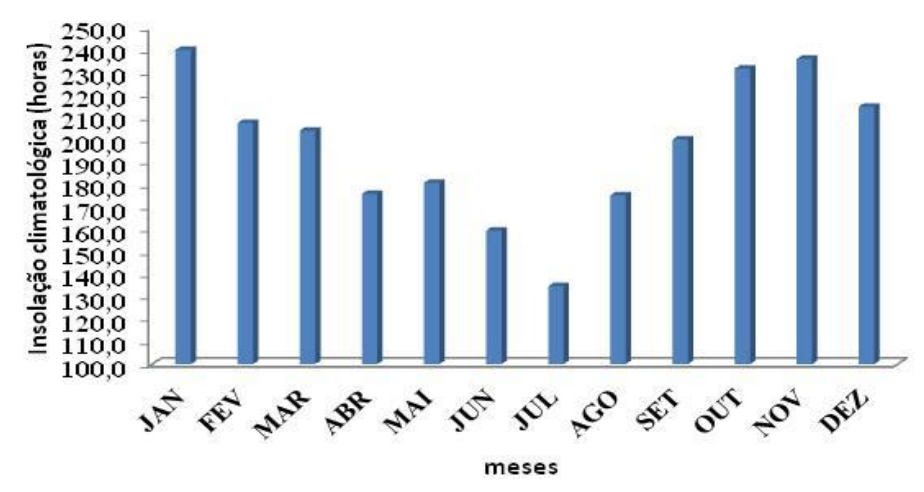

Fonte: Medeiros (2022).

A nebulosidade total é a fração da abóbada celeste oculta pelo conjunto das nuvens visíveis. Com os registros das observações meteorológicas dos tipos de nuvens $\left(\mathrm{c}_{\mathrm{l}}\right)$ nuvens baixas, $\left(\mathrm{c}_{\mathrm{m}}\right)$ nuvens médias e $\left(\mathrm{c}_{\mathrm{h}}\right)$ nuvens altas, por meios do algarismo $(0-10)$ foram possíveis estimar a nebulosidade para o município de Matinhas.

Na Figura 9, tem-se o gráfico da climatologia da cobertura de nuvens total para o município de Matinhas.

Observa-se que as maiores concentrações de nebulosidade estão nos meses de abril a julho com oscilações entre 0,62 a 0,82 décimos, nos meses de outubro, novembro e dezembro têm-se uma variabilidade de cobertura de nuvens entre 0,25 a 0,30 décimos. A média anual da nebulosidade para o município de Matinhas é de 0,81.

Figura 9. Gráfico da climatologia da nebulosidade, para o município de Matinhas.

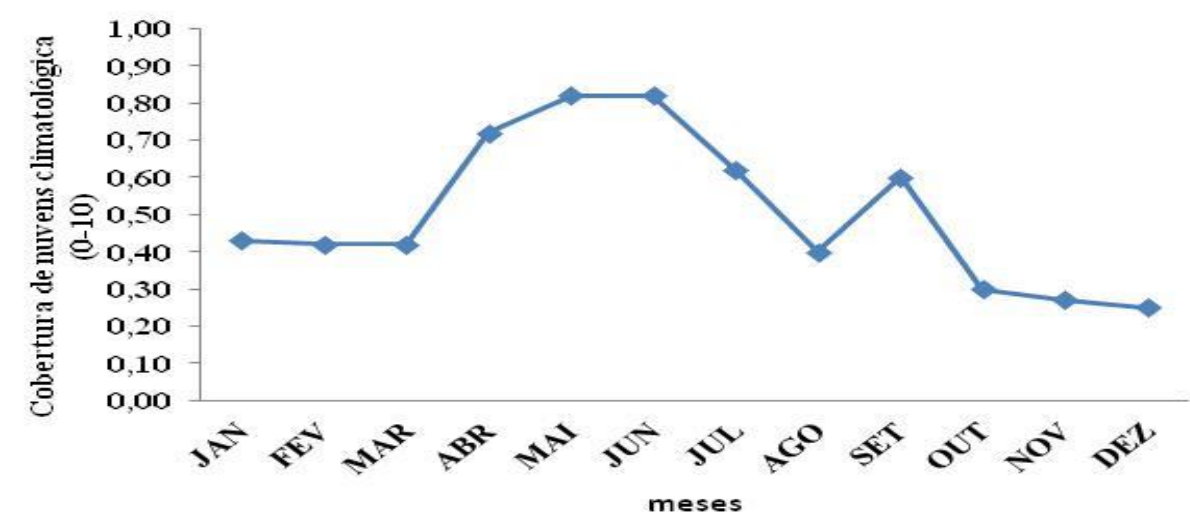

Fonte: Medeiros (2022). 


\section{Balanço Hídrico}

Na Figura 10 observa-se o gráfico da precipitação climatológica, evapotranspiração potencial e evaporação real, segundo (Thornthwaite 1948) para o município de Matinhas.

O resultado do balanço hídrico foi obtido através das climatológicas de temperatura e das precipitações médias da área municipal.

O clima é do tipo tropical chuvoso, com verão seco. A estação chuvosa se inicia em janeiro/fevereiro com término em setembro, podendo se estender até outubro.

Os excedentes hídricos para a CAD de 100 ocorrem nos meses de junho e julho, devido ao solo esta já está em sua capacidade de campo máxima, onde começa o escoamento os excedentes, ou seja, para a agricultura irrigada qualquer destas laminadas utilizadas neste período provoca excesso visto que o solo já tem capacidade de campo.

Tabela 3 mostra resultados do balanço hídrico para CAD de $100 \mathrm{~mm}$.

Tabela 3 - Resultado do balanço hídrico para CAD’ de 100 no município de Matinhas, onde DEF (Déficit hídrico) e EXC (Excedente hídrico).

\begin{tabular}{lcccccccccccc}
\hline Meses & jan & fev & mar & abr & mai & jun & jul & ago & set & out & nov & dez \\
\hline Deficit & 33,0 & 16,2 & 30,2 & 0,0 & 0,0 & 0,0 & 0,0 & 0,0 & 14,8 & 59,2 & 84,4 & 98,7 \\
Excedente & 0,0 & 0,0 & 0,0 & 0,0 & 0,0 & 0,0 & 11,2 & 49,1 & 0,0 & 0,0 & 0,0 & 0,0 \\
\hline
\end{tabular}

Fonte: Medeiros (2022).

O gráfico do balanço hídrico para a CAD's de $100 \mathrm{~mm}$ e suas representatividades das deficiências, excedentes, retirada reposição hídrica para o período de anos 2000 a 2018 para o município de Matinhas.

Figura 10. Gráfico da deficiência, excedente, retirada e reposição hídrica, segundo Thornthwaite \& Mather para o município de Matinhas, CAD $100 \mathrm{~mm}$.

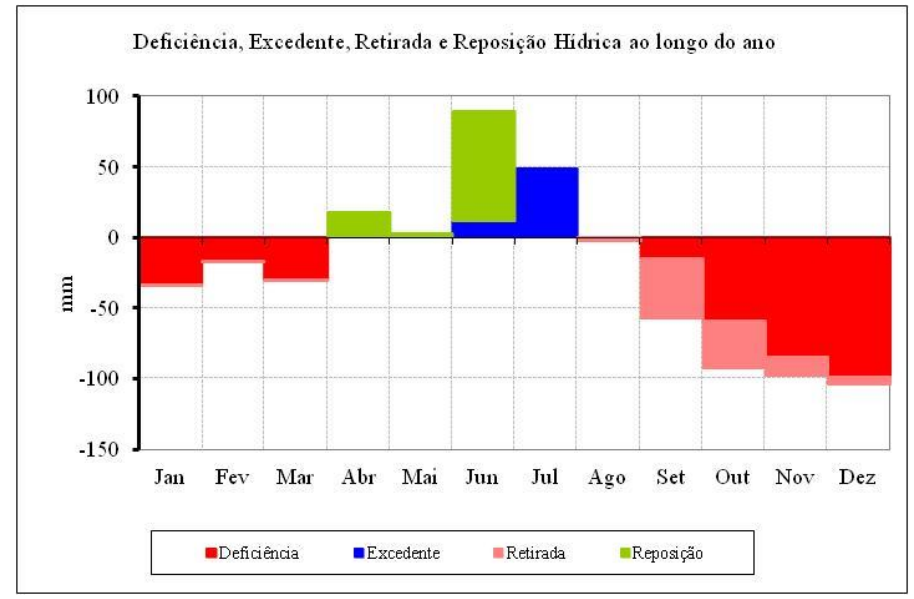

Fonte: Medeiros (2022).

\section{Conclusões}

A CAD de $100 \mathrm{~mm}$ é mais apropriada para os plantios de bananeiras, fruticultura e citrus;

Utilizando-se da CAD estudadas no setor da irrigação pode ocorrer redução nas tarifas elétricas, tempo de redução de utilização de bomba d'água e racionalização de água aplicada as culturas; 
Os dados obtidos neste trabalho confirmaram a vocação do município de Matinhas nas atividades da citricultura voltada, notadamente, para a exploração da tangerina e permitiram identificar e classificar os polos ou sítios que se sobressaem na atividade dessa frutífera;

As rajadas de vento superiores a $10 \mathrm{~ms}^{-1}$ ocorrem com maiores predominâncias nos meses de agosto a fevereiro e podem causar estragos as leguminosas e hortaliças da área estudada, tais como ocorrendo acamamento e desfolhagem;

As flutuações das temperaturas do ar máximas, mínimas, médias e da amplitude térmica indicam a ocorrências de possíveis formações de orvalhos acima da normalidade em quase todos os meses do ano, com maiores significâncias nos meses de março a agosto, fato este que pode vim a prejudicar a qualidade dos produtos citricos para o mercado;

A umidade relativa do ar deve-se ter-se cuidados especiais nos meses de outubro a dezembro;

Para o município de Matinhas tem-se água abundante, sol e umidade relativa do ar apropriada para desenvolvimento, floração, enchimentos dos frutos e frutos saudáveis e de qualidade para a alimentação humana;

Para evitar determinadas pragas e os fitopatógenos que evoluí com as plantas, o microclima ideal para a planta, normalmente é ideal para as pragas, porém se a planta não sofre estresse e consegue acumular matéria seca ela tende a ficar mais resistente às moléstias, visto que estão sendo controlada temperatura de solo e sua umidade, fatores estes que auxiliam no desenvolvimento de pragas e do estresse das cultivares;

As condições de clima e solo do município dá um alto potencial de produção de frutas e citros frescas para o mercado interno e externo, com um grande potencial para a fruticultura e os citros tropical irrigada ou de cerqueiro com frutas de excelente qualidade;

As elevadas produtividades e a qualidade de nossas frutas vêm facilitando a abertura dos mercados mais exigentes do mundo. O município poderá representar o berço da citricultura paraibana e disputar o mercado de frutas "IN NATURA" e produtos derivados;

\section{Referencias}

AESA. (2022). Agência Executiva de Gestão das Águas do Estado da Paraíba. http://geo.aesa.pb.gov.br“.

Alvares, C. A., Stape, J. L., Sentelhas, P. C., Gonçalves, J. L. M. \& Sparovek, G. (2014). Köppen's climate classification map for Brazil. Meteorologische Zeitschrift. 22, 711-28.

Assis, J. M. O., Souza, W. M. \& Sobral, M. C. M. (2015). Climate analysis of the rainfall in the lower-middle stretch of the São Francisco river basin based on the rain anomaly index. Revista Brasileira de Ciências Ambientais. 2, 188-202.“. Autores, coloquem em itálico o nome da revista "Revista Brasileira de Ciências Ambientais".

Cardoso, G. M. \& Justino, F. (2014). Simulação dos componentes da evapotranspiração sob condições climáticas atuais e de cenários climáticos futuros de aquecimento global com o uso de modelos de clima-vegetação. Revista Brasileira de Meteorologia. 29(1), 85-95. http://doi.org/10.1590/S010277862014000100009

Costa, M. N. M., Medeiros, R. M. \& Gomes Filho, M. F. (2015). Variabilidade da evaporação no tanque classe "A" entre o período de 1976 a 2011 e suas comparações com as três décadas e meia e com o ano de 2011 no município de Teresina, Piauí. $7^{\circ}$ Workshop de Mudanças Climáticas do Estado de Pernambuco e $4^{\circ}$ Workshop Internacional sobre Mudanças Climáticas e Biodiversidade. Recife-PE, CD RON. P. 107-23.

Cavalcanti, E. P., Silva, V. P. R., \& Sousa, F. A. S. (2006). Programa computacional para a estimativa da temperatura do ar para a região Nordeste do Brasil. Revista Brasileira de Engenharia Agrícola e Ambiental, 10(1), 140-147.

Cavalcanti, E. P., \& Silva, E. D. V. (1994). Estimativa da temperatura do ar em função das coordenadas locais. IN: Congresso Brasileiro de Meteorologia. 8. 1994. Belo Horizonte, Anais... SBMET, 1, 154-157.

Dantas, G. F., Oliveira, V. M. R., Dalri, A. B., Palaretti, L. F., Santos, M. G., \& Faria, R. T. T. (2016). Desempenho de métodos na estimativa de evapotranspiração de referência para o estado da Paraíba, Brasil. Irriga, 21(3), 481-490.

Food And Agriculture Organization - FAO. Faostat Statistical databases: Agriculture. 2002. <http://apps.fao. org>.

Hallal, M. O. C., Schoffel, E. R., Brixner, G. F., Raduns, A. L. Estimativa da evapotranspiração de referência e sua relação com a precipitação ocorrida na região de Pelotas-RS. Irriga, Botucatu, 18(1), 85-98, 2013. http://doi.org/10.15809/irriga.2013v18n1p85

IPCC. (2014). Impacts, Adaptation, and Vulnerability. Part B: Regional Aspects. Working Group II Contribution to the Fifth Assessment Report of the Intergovernmental Panel on Climate Change. Intergovernmental Panel on Climate Change (IPCC). 
Intergovernmental Panel on Climate Change Climate Change 2007: The Physical Science Basis, Contribution of Working Group I to the Fourth Assessment Report of the Intergovernmental Panel on Climate Change, edited by S. Solomon et al., Cambridge Univ. Press, Cambridge, U. K. 2014.

IPCC. (2007). Intergovernmental Panel on Climate Change. Climate Change 2007: Working Group I: The Physical Science Basis (Summary for Policymakers). Cambridge.

Köppen, W., \& Geiger, R. (1928). Klimate der Erde. Verlag Justus Perthes.

Köppen, W. (1931). Grundriss der Klimakunde: Outline of climate science. Walter de Gruyter, 388p

Kozmhinsky, M., Medeiros, R. M., Holanda, R. M., \& Silva, V. P. Average insolation interpolated by the krigagem method for the state of Pernambuco Brazil. Journal of Hyperspectral Remote Sensing. 8(2). 334-344.

Lazinski, L. R. Variabilidade da utilização do modelo Soygro para a região de Londrina, PR. Dissertação (Mestrado), Escola Superior de Agricultura "Luiz de Queiroz", Universidade de São Paulo, 1993. Piracicaba/SP.

Laranja Brasil. Surgimento da laranja no Brasil.:<www.laranjabrasil.com.br. $>$.

Lopes, E. B., Albuquerque, I. C., \& Moura, F. T. (2007) Perfil da citricultura de Matinhas, PB, visando ao mercado nacional. Rev. Tecnol. \& Ciên. Agropec., $1(1), 1-7$.

Machado, T. S., Neves, S. M. A. S., Seabra Jr, S., \& Neves, R. J. (2017). Zoneamento agroclimático do melão na região sudoeste de Mato Grosso. Revista Brasileira de Climatologia. 13(20).

Matos, R. M., Silva, J. A. S., \& Medeiros, R. M. (2014). Aptidão climática para a cultura do feijão caupi do município de Barbalha - CE. Revista Brasileira de Agricultura Irrigada, 8(6), 422-431.

Marengo, J. A, Schaeffer, R, Zee, D, Pinto, H. S, (2015). Mudanças climáticas e eventos extremos no Brasil. http://www.fbds.org.br/cop15/FBDS_MudancasClimaticas.pdf.

Marengo, J. A., \& Camargo, C. C. (2008). Surface air temperature trends in Southern Brazil for 1960 - 2002. International Journal of Climatology. 28, 893904.

Medeiros, R. M., Cavalcanti, E. P., (2020). Tendência climática das temperaturas do ar no município de Bom Jesus do Piauí, Brasil. Research, Society and Development, 9(7):1-23, e315973882.

Medeiros, R. M., Holanda, R. M., Viana, M. A., SILVA, V. P. (2018). Climate classification in Köppen model for the state of Pernambuco - Brazil. Revista de Geografia 35, 219 - 234.

Medeiros, R. M. (2018). Insolação decadal para o município de Recife-PE, Brasil. Rev. Geogr. Acadêmicas, 12(2). $124-137$.

Medeiros, R. M. (2017). Amplitudes térmicas e sua oscilação mensal na grande metrópole Recife-PE, Brasil. Revista Paisagens \& Geografias. 2(1): 31-45.

Medeiros, R. M. (2016). Estudo agrometeorológicos para o Estado Paraíba. p.138. Distribuição avulsa

Menezes, F. P., Fernandes, L. L., \& Rocha, E. J. P. (2015). O uso da estatística para regionalização da precipitação no estado do Pará, Brasil. Revista Brasileira de Climatologia. 11(16).

Menezes, F. P., \& Fernandes, L. L. (2016). Análise de tendência e variabilidade da precipitação no Estado do Pará. Enciclopédia Biosfera, 13(24), 1580-1591.

Moura, Q. L., Ruivo, M. L. P., \& Rodrigues, H. J. B. (2015). Variação sazonal da população de bactérias e fungos e dos teores de nitrato de amônio do solo nos sítios do LPA e PPBIO na Amazônia Oriental. Revista Brasileira de Meteorologia, 30(3), 265-274.

Muniz, R. A., Souza, E. F., Mendonça, J. C., Esteves, B. S., \& Liusada, L. L. (2014) Balanço de energia e evapotranspiração do capim Moçamba sob sistema de pastejo rotacionado. Revista Brasileira de Meteorologia, 29(1), 47-54, 2014. http://doi.org/10.1590/S0102- 77862014000100005

Nobre, C. A., \& Assad, E. D. (2005). O aquecimento global e o impacto na Amazônia e na agricultura brasileira. INPE e Print, 1(2), 251-257, <http://eprint.sid.inpe.br/col/sid.inpe.br/ePrint@80/2005/09.12.12.51/doc/v1.//doc/v1.pdf>.

Ortolani, A. A., \& Camargo, M. B. P. (1987). Influência dos fatores climáticos na produção. in: Castro, P.R.C., Ferreira, S.O., Yamada, T. (ed.) Ecofisiologia da produção agrícola. Piracicaba, SP: Associação Brasileira para Pesquisa da Potassa e do Fosfato, Cap.4, p.7 1-79.

Pereira, M. C. A., Melo, D. F., Meló, R. G. C., Silva, R. F. B., \& Farias, S. A. R. Mesorregiões da Paraíba e suas necessidades de captação de água de chuva. In: Simpósio brasileiro de captação e manejo de água de chuva, 8. 2012, Campina Grande. Anais... Campina Grande: FIEP, 2012. p. 01-06.

Piazza, G. A., Pinheiro, A., Kaufmann, V., Torres, E., Venzon, P. T., Gotardo, R., Baptista, G. C. Z., \& Knaesel, K. M. (2017) Histerese intranual das variáveis hidroclimáticas da Bacia do Ribeirão Concórdia, Santa Catarina, Sul do Brasil. In: Simpósio Brasileiro de Recursos Hídricos, 20. Anais. Florianópolis: UFSC, 2017.

Ramos, H. C., Dallacort, R. Neves, S. M. A. S. Dalchiavon, F. C., SantI, A., Vieira, F. F. (2017). Precipitação e temperatura do ar para o estado de Mato Grosso utilizando krigagem ordinária. Revista Brasileira de Climatologia. 13(20).

Righetto, A. M. (1998). Hidrologia e Recursos hídricos. EESC/USP.

Rossato, M. S. (2011). Os climas do Rio Grande do Sul: variabilidade, tendências e tipologia. 240f. Tese (Doutorado) - Universidade Federal do Rio Grande do Sul. Instituto de Geociências. Programa de Pós-Graduação em Geografia, Porto Alegre, RS-BR. 
Research, Society and Development, v. 11, n. 2, e14411225651, 2022

(CC BY 4.0) | ISSN 2525-3409 | DOI: http://dx.doi.org/10.33448/rsd-v11i2.25651

Rossetti, V. V. Manual ilustrado de doenças dos citros. FEALQ, 2001. $207 \mathrm{p}$

Rossi, JR. C. Aspecto da cultura de tangerinas no Sul de Minas Gerais. 54

Sediyama, G. C. Evapotranspiração: Necessidade de água para plantas cultivadas. Brasília - DF: ABEAS/UFV, 1996. 176p. (curso de engenharia da irrigação, módulo 4).

Tucci, C. E. M. (2005). Modelos hidrológicos- (2a ed.), Editora da UFRGS, 669p. 